\title{
PROGRAMA DE CONTROLE DE SURTO DE ESCORPIÃO TITYUS SERRULATUS, LUTZ E MELLO 1922, NO MUNICÍPIO DE APARECIDA, SP (SCORPIONES, BUTHIDAE)
}

\author{
Elieth Floret Spirandeli Cruz, Clóvis R. Winther Yassuda, Jorge Jim e \\ Benedito Barraviera
}

\begin{abstract}
Os autores propuseram para o municipio de Aparecida, vale do Rio Paraíba, $S P$, regiāo endêmica do Tityus serrulatus, um programa de controle do escorpionismo. Foram estudados a presença de focos do escorpião no campo e na cidade, as alterações ambientais periféricas à zona urbana e os novos ambientes de procriação e dispersão destes artrópodes. Além disso, foram avaliados os problemas básicos de infra-estrutura, tais como o acondicionamento e a coleta do lixo urbano público e domiciliar, o saneamento básico (esgotos e galerias pluviais) e a situação dos terrenos baldios e as construções da zona urbana. Após estudo epidemiológico, foram propostas medidas educativas, que constaram da confecção e distribuição de folbetos, de mutirões de limpeza, de visitas domiciliares e do engajamento de professores e alunos da rede de ensino pública e privada na campanba. Nos locais onde existiam focos de alto risco, em especial nas pré-escolas, foi proposto o emprego do controle quimico. Dentro das normas sanitárias vigentes para a zona urbana, foi proposto ainda, o uso de predadores naturais no combate. Os autores concluem que as ações devem ser integradas $e$ continuadas de forma ininterrupta por vários anos e propõem ação conjunta com a campanba da dengue. $A$ instituição de uma semana por ano dedicada ao estudo do escorpionismo nas escolas dos municipios onde ocorre o problema seria uma medida educativa que viria contribuir sobremaneira para a prevenção dos acidentes e controle do escorpionismo.
\end{abstract}

Palavras-chaves: Escorpionismo. Tityus serrulatus. Epidemiologia. Programa de controle.

O município de Aparecida, localizado à margem do Rio Paraíba do Sul, no Estado de São Paulo, apresenta desde há muito tempo surtos de infestação por escorpiões. De acordo com os registros históricos, entre 1949 e 1963 , - escorpionismo já era um problema na região. Relata o Padre e Reitor do Santuário Nacional de Nossa Senhora Aparecida, Jadir Teixeira da Silva, que em 1960 cada cinco escorpiões capturados pela população podiam ser trocados por uma bola de borracha. Em 1981, o Jornal Vale Paraibano, noticiou em diversas oportunidades os seguintes temas:

Departamento de Zoologia do Instituto de Biociências de Botucatu, Departamento de Doenças Tropicais e Diagnóstico por Imagem da Faculdade de Medicina de Botucatu, Centro de Estudos de Venenos e Animais Peçonhentos - CEVAP, da Universidade Estadual Paulista UNESP, e Prefeitura da Estância Turística e Religiosa de Aparecida (SP) - PETRA.

Endereco para correspondência: Dra. Elieth Floret Spirandeli Cruz. Depto de Zoologia do Instituto de Biociências de Botucatu, UNESP, 18618-000, Botucatu (SP). Recebido para publicação em 23/05/94.
"Aparecida: muito lixo, muitas moscas"; "Surtos de insetos e ratos preocupam Aparecida"; "Escorpiões invadem Aparecida". Em 1991, os órgãos de Saúde Pública do Vale do Paraíba registraram no município de Aparecida cerca de 15 casos de acidentes causados por escorpiões. Como a população do município é cerca de 35.000 habitantes, este número equivale a um índice de incidência de 43 casos por 100.000 habitantes. Este índice foi o maior registrado para a microrregião administrativa do Vale do Paraíba, perdendo apenas para o de Belo Horizonte (MG), o maior do país.

Com a construção da Basílica Nacional de Aparecida, iniciada em 1946, houve um aumento significativo da população flutuante do município. Atualmente Aparecida recebe cerca de 5 milhões de romeiros por ano, principalmente nos finais de semana e feriados prolongados.

Baseado nestas considerações a Prefeitura Municipal de Aparecida, de um lado preocupada com o aumento significativo do 
Cruz EFS, Yassuda CRW, Jim J, Barraviera B. Programa de controle do surto de escorpião Tityus serrulatus, Lutz e Mello 1922, no municipio de Aparecida, SP, (Scorpiones, Buthidae). Revista da Sociedade Brasileira de Medicina Tropical 28:123-128, abr-jun, 1995.

número de acidentes escorpiônicos, e por outro lado, devido a enorme população flutuante que visita o município, convidou em 1991 os pesquisadores do Centro de Estudos de Venenos e Animais Peçonhentos da UNESP - CEVAP para desenvolver um programa diagnóstico do escorpionismo na cidade, e propor uma metodologia de controle.

\section{ETIOLOGIA}

A espécie de escorpião mais comum na região do Vale do Paraíba, de acordo com a literatura ${ }^{2}$ é Tityus serrulatus, Lutz e Mello, 1922. Esta espécie embora primitivamente habitante de cerrado e campos abertos, tornou-se bem adaptada à vida domiciliar urbana, possivelmente em decorrência da rápida e desenfreada colonização pelo homem das regiões originalmente ocupadas pelo artrópode. Além disso, esses animais adaptaram-se facilmente às condições oferecidas pelas moradias humanas, tais como grande número de abrigos (lixo, entulho, pilhas de tijolos e telhas, etc.), e alimentação farta (baratas) ${ }^{123}$.

Tityus serrulatus se reproduz de maneira peculiar através de um complexo processo denominado partenogênese, isto é, os óvulos desenvolvem-se no organismo materno sem a fertilização pelo macho ${ }^{4}$, o qual inexiste na natureza. As fêmeas sozinhas gestam e parem durante todo o ano, ninhadas de até 24 filhotes.

A adaptação da espécie às condições urbanas, aliada ao seu modo de reprodução e às precárias condições de higiene e saneamento básico encontradas principalmente em bairros de periferia, facilitaram a disseminação destes artrópodes em grandes aglomerados urbanos.

\section{ESTUDO EPIDEMIOLÓGICO}

Os pesquisadores do CEVAP e a Prefeitura Municipal de Aparecida realizaram um minucioso levantamento epidemiológico com os seguintes objetivos: localização do escorpião no campo e na cidade; avaliação de condições propícias a infestação na região; avaliação das condições sócio-econômicas e educacionais da população sujeita ao escorpionismo

Foram diagnosticadas as seguintes situações:
- Presença dos escorpiões no campo: foram visitadas a Fazenda do Bispado, distando cerca de $5 \mathrm{Km}$ do centro do município e a Escola Rural do Bonfim, distando cerca de $20 \mathrm{~km}$. Nestas localidades foi verificada a presença dos artrópodes nos barrancos de estradas de acesso. Citações da população local como ocorrência em cupinzeiros e sob moitas de capim foram anotadas. Na Escola do Bonfim, foi registrada a presença dos animais na calçada existente ao redor da Escola, dentro da sala de aula, na cozinha e nos banheiros.

- Presença de focos urbanos: foram visitados diversos bairros da cidade, inclusive àqueles com registros de acidentes. No centro da cidade foram encontrados escorpiões no interior de túmulos e em pilhas de tijolos dentro do cemitério, no quintal de residências, sob os estoques de madeira de uma Fábrica de papel e celulose e sob os dormentes da Estrada de Ferro que atravessa o município. Caso interessante foi registrado de um morador que em quarenta anos de residência na mesma casa e com o hábito de criar galinhas soltas no quintal, nunca observou escorpião em sua casa, embora fosse vizinho de uma paciente acidentada. Deve ser salientado que Tityus serrulatus foi a única espécie registrada pela equipe no município.

- Lixo público: avaliou-se o lixo deixado semanalmente pelos romeiros, que na sua maioria não o depositam em locais apropriados. Este lixo fica exposto durante algum tempo nas ruas, praças, pátio de estacionamento da Basílica Nacional, sob os bancos do jardim, constituindo fonte de alimento das baratas, que por sua vez servem de alimento para os escorpiões.

- Desequilibrio ambiental: foi avaliado $o$ desmatamento da região, que vem ocorrendo há muito tempo, sem que se tenha notado alguma proposta de recuperação da vegetação original. Isto, por sua vez, pode ter causado a diminuição dos inimigos naturais ou até o desaparecimento de animais que ocupariam o mesmo nivel do escorpião na cadeia alimentar. No perímetro urbano a formação de novos loteamentos é fator de destruição do habitat natural dos escorpiões, como é o caso de cupinzeiros, barrancos, pedras e touceiras de capim, acarretando, em última análise, o deslocamento desses artrópodes à procura de novos abrigos. O vale do Paraíba é antiga 
Cruz EFS, Yassuda CRW, Jim J, Barraviera B. Programa de controle do surto de escorpião Tityus serrulatus, Lutz e Mello 1922, no município de Aparecida, SP, (Scorpiones, Buthidae). Revista da Sociedade Brasileira de Medicina Tropical 28:123-128, abr-jun, 1995.

região agro-pastoril, continuamente desmatada, sendo que a degradação ambiental ocorre ainda hoje pela poluição do próprio Rio Paraíba com dejetos industriais e urbanos.

\begin{abstract}
- Pesquisa de novos ambientes de procriação
e dispersão: devido ao registro de grande número de acidentes escorpiônicos no interior das residências, especialmente nos banheiros, levantou-se a hipótese de que os escorpiões pudessem chegar às residências através das galerias de esgoto. Nesse sentido, em duas oportunidades os pesquisadores do CEVAP visitaram durante a noite, uma das redes de esgoto, munidos de lanternas de luz normal e ultra-violeta, à procura dos escorpiões. Constatou-se, além da antiguidade da rede de esgotos e galerias pluviais, a ocorrência destes artrópodes no local corroborando a hipótese inédita dos pesquisadores ${ }^{6}$.
\end{abstract}

\section{- Problemas básicos de infra-estrutura: foi} avaliado na zona urbana o acondicionamento do lixo doméstico, o seu destino e o estado em que se encontram os terrenos baldios em relação à presença de muros e calçadas, além da presença de entulhos e lixo doméstico. Verificou-se que a maioria da população não tem o hábito de colocar o lixo em sacos plásticos entregando-o à Prefeitura em latões abertos e permitindo assim o acesso ao lixo de animais que dele se alimentam, principalmente as baratas. Os terrenos urbanos, principalmente àqueles sem qualquer construção, encontram-se sujos, cheios de entulho e lixo e raramente são murados, facilitando o refúgio e a procriação de escorpiōes e outros animais.

\section{- Conscientização da população a respeito do}

problema: durante as operações denominadas mutirão de limpeza e casa a casa, avaliou-se através de entrevista, a real importância que a população dá ao escorpionismo. Constatou-se que a mesma convive com o problema sem no entanto conhecer sua verdadeira gravidade.

\section{AÇÕES E PROPOSTAS}

Após o levantamento epidemiológico preliminar foi constatada a presença dos escorpiões Tityus serrulatus no campo e na zona urbana do município de Aparecida. Deve-se salientar que esta foi a única espécie de escorpião encontrada na região pela equipe.

Os pesquisadores do CEVAP em conjunto com o Escritório Regional de Saúde - ERSA,
Regional de Guaratinguetá (SP) e a Superintendência de Campanhas de Endemias - SUCEN, Regional de Taubaté (SP) sugeriram, de maneira integrada, medidas preventivas, medidas corretivas do ambiente e medidas educacionais com o objetivo de controlar o problema do escorpionismo, proporcionando níveis de infestação aceitáveis do ponto de vista epidemiológico.

$\hat{E}$ necessário lembrar que não existem medidas de controle específicas para o escorpionismo, pois elas se constituem nos mesmos princípios básicos de Saúde Pública, a serem respeitados em sociedades modernas. Assim as ações propostas foram as seguintes:

- Lixo doméstico: o acondicionamento adequado do lixo em sacos plásticos, que devem ser mantidos fechados, pode evitar que este se torne foco de atração d artrópodes, entre eles, as baratas. Entretanto, como a coleta em saco plástico não é hábito da população de Aparecida e tendo em vista o seu grau de importância, foi sugerido à Prefeitura Municipal e ao Órgão Legislativo que tomassem a iniciativa de normatizar o assunto.

- Regulamentação sobre terrenos baldios: foi sugerido à Prefeitura a legislação e a fiscalização da limpeza dos terrenos baldios, seus calçamentos e a colocação de muros quando necessário.

- Controle químico dos escorpiões: em algumas escolas localizadas no centro da cidade, devido ao grande de número de escorpiões capturados pelos alunos, e a difícil implantação do método físico da busca ativa, os pesquisadores do CEVAP em conjunto com a Prefeitura Municipal e com a SUCEN, optaram pela aplicação de inseticida. $O$ produto escolhido foi o piretróide à base de delthamethrine, semelhante àqueles utilizados em campanhas de desinsetização. Foram pulverizadas as salas de aula e o pátio das escolas, observando-se efeito residual do veneno de aproximadamente um mês, periodo no qual não se observou a presença dos escorpiões.

- Uso de predadores naturais: o uso de inimigos naturais no combate ao escorpião (sapos, corujas, macacos, etc.) é pouco divulgado pela literatura científica. Por outro lado, as galinhas, predadoras em potencial destes aracnídeos poderiam em determinadas 
Cruz EFS, Yassuda CRW, Jim J, Barraviera B. Programa de controle do surto de escorpião Tityus serrulatus, Lutz e Mello 1922, no municipio de Aparecida, SP, (Scorpiones, Buthidae). Revista da Sociedade Brasileira de Medicina Tropical 28:123-128, abr-jun, 1995.

condições ser utilizadas como método de controle. Apesar dos escorpiões serem de hábitos noturnos e as galinhas diurnas, estas últimas no ato de ciscar podem remover e devorar os animais escondidos em frestas, debaixo de folhas e entulhos. Dessa forma, nas residências com quintais grandes, a criação de galinhas poderia ajudar no combate a estes artrópodes, obedecidas as normas sanitárias para a criação de animais domésticos nas cidades.

No ano de 1991, diante do grave problema do escorpionismo, a Prefeitura, por iniciativa própria, distribuiu à população de alguns baitros aproximadamente 800 galinhas caipiras. O fato, na época revestido de grande sensacionalismo jornalístico, não pode ter sua eficácia avaliada. Os pesquisadores do CEVAP avaliaram a distribuição das galinhas como sendo mais uma medida educativa, quando reforçou à população o conceito de "cadeia alimentar", conscientizando-a da importância dos inimigos naturais no equilíbrio da população de artrópodes.

- Medidas educativas: estas possivelmente sejam as mais importantes e mais dificeis de serem implantadas na população. Assim a campanha educativa envolveu a confecção e a distribuição de folhetos, visitas domiciliares, mutirões de limpeza, cursos, palestras, entrevistas nos principais meios de comunicação da cidade, exposições didáticas e a participação das escolas na elaboração de material educativo.

- Folheto explicativo: foi padronizado um folheto contendo explicações sobre a espécie de escorpião registrada na região e os seus hábitos, os cuidados com as crianças acidentadas e a urgência no atendimento médico, os primeiros socorros a serem tomados, as medidas preventivas básicas e por fim a captura dos animais e o seu encaminhamento aos órgãos competentes. Foram distribuídos 20.000 folhetos à população, sendo 7.000 deles junto com a conta de luz, 10.000 entre professores e alunos das escolas e 3.000 deles na operação "casa a casa".

- Operação "casa a casa": aproveitando a campanha contra a dengue, quatro equipes da Prefeitura, previamente treinadas pelo CEVAP e SUCEN trabalharam aproximadamente 7.000 estabelecimentos. Esta operação individualizada, adaptou a linguagem, motivou a população, apresentou sugestões de melhoria ao folheto, reforçou o comportamento e orientou àqueles que desconheciam o problema. Nesta operação foram distribuídos 3.000 folhetos educativos.

Mutirão de limpeza: as equipes do CEVAP e da Prefeitura em conjunto com agentes sanitaristas auxiliaram os moradores na identificação de criadouros de escorpiões, que foram eliminados pela própria população. A Prefeitura colocou à disposição da população caminhões basculantes, caminhão tanque, retroescavadeira e auxiliou na utilização destes, quando necessário. Com o desenvolvimento do trabalho em alguns pontos da cidade, diversos bairros tomaram a iniciativa de realizar seus próprios mutirôes de limpeza, que foram imediatamente apoiados pela comissão executora do projeto.

- Encontro Educacional: este encontro foi intitulado de "1을 Encontro Educacional sobre Escorpionismo de Aparecida (SP)" e durou três dias. O objetivo foi de movimentar toda rede municipal e estadual de ensino, com aproximadamente 10.000 alunos, promovendo atividades extra-classe, levando principalmente às crianças informações gerais sobre o assunto, com o intuito final destas influenciarem os familiares adultos em casa. O programa do encontro constou das seguintes atividades: No primeiro dia, treinamento dos professores em anfiteatro ministrando-se as seguintes aulas: "Epidemiologia do escorpionismo no Brasil"; "Biologia e ecologia dos escorpiões"; "Métodos de prevenção e controle do escorpionismo". Estas palestras tiveram a duração total de 8 horas.

Nos segundo e terceiro dias os alunos, professores, pesquisadores do CEVAP, monitores da Prefeitura e voluntários da população participaram de uma exposição didática em parte montada pelo CEVAP e em parte pelos alunos com a motivação e a ajuda dos professores. Durante a exposição foram desenvolvidas as seguintes atividades:

- distribuição de 10.000 folhetos ao público visitante;

- estudo pelos alunos dos painéis educativos do CEVAP, montados com fotografias e textos explicativos sobre escorpionismo;

- projeção de filmes educativos sobre escorpionismo rodados em Aparecida (SP); 
Cruz EFS, Yassuda CRW, Jim J, Barraviera B. Programa de controle do surto de escorpião Tityus serrulatus, Lutz e Mello 1922, no municipio de Aparecida, SP, (Scorpiones, Buthidae). Revista da Sociedade Brasileira de Medicina Tropical 28:123-128, abr-jun, 1995.

- apresentação de trabalhos educativos sobre escorpionismo, criados e desenvolvidos pelos próprios alunos;

Ao final do encontro educacional e de comum acordo com os professores, foi sugerido a introdução do tema "Escorpionismo" como matéria obrigatória para todos os alunos de primeiro e segundo graus do municipio, inclusive com cobrança do aprendizado em avaliações. Além disso, foi fornecido à Secretaria Municipal de Educação e Cultura de Aparecida material didático, slides e filmes, sobre o tema em questão, para uso das escolas interessadas.

\section{CONCLUSÕES}

O controle preconizado para o escorpionismo em determinada região deve ser monitorado ao longo do ano todo, devendo ser mais intenso nos períodos que antecedem, ou mesmo durante as épocas em que se têm demonstrado um maior risco para a população, em geral na estação chuvosa do ano. Os autores entendem que o problema é basicamente sócio-cultural e os programas de controle deverão ser aplicados continuadamente ano após ano e só apresentarão resultados positivos quando a população apresentar mudanças comportamentais que se refletirão na diminuição dos índices de acidentes e de infestação.

Deve ser salientado que as ações propostas de controle devem ser integradas $e$ continuadas de forma ininterrupta por vários anos, até que possam ser verificados indices aceitáveis de infestação. A experiência de Aparecida mostrou ser possível, nos municípios onde ocorre o problema, a integração entre as campanhas de combate ao escorpionismo com os de controle à dengue. As situações epidemiológicas destas duas endemias se sobrepõem em diversas oportunidades e pode-se utilizar a mesma equipe treinada para ambas as funções. Nos municípios onde o problema ocorre poder-seia instituir a semana do escorpião, objetivando relembrar a população, ano após ano, da necessidade de manter-se vigilante para o problema. Esta semana deve anteceder os meses de maior ocorrência dos escorpiões. Além disso, o trabalho dos professores de primeiro e segundo graus, mantendo e cobrando o tema em apreço anualmente dos alunos, contribuiria sobremaneira para a prevenção dos acidentes e o combate aos artrópodes.

Por fim, um vitória importante da população de Aparecida foi a instalação do posto de soro anti-escorpionico no município. Hoje, os doentes picados podem ser atendidos de maneira precoce e adequada, recebendo inchusive o tratamento específico com soro anti-escorpiônico, quando indicado pelo médico assistente.

\section{SUMMARY}

A scorpion control program was proposed for the town of Aparecida (SP), an endemic region of Tityus serrulatus. Clusters of scorpions in urban and rural areas, environmental degradation of the town's outskirts and new scorpion procreation and dispersal babitats were studied. In addition, infrastructure problems such as the disposal and collection of residential and municipal refuse, sanitation (sewage and storm sewer), condition of vacant lots and constructions in the urban area were evaluated. After an epidemiological study, educational measures such as the distribution of pampblets, cleaning group work, visits to residences and cooperation from High School teachers and students were also suggested. Chemical control was indicated in high-risk sites, especially those of nearschool buildings. Furtbermore, the use of natural predators was also mentioned within the present sanitation regulations for urban areas. The authors assert that these procedures must be integrated and continued aninterrmiptedly for several years. They also suggest a collaborative work with those responsible for the dengue erradication program, as well as the institution of the "scorpion study week", whicb would greatly contribute to the education of the population, to preventive programs and to scorpion control.

Key-words: Tityus serrulatus. Control program Epidemiology of scorpions.

\section{REFERÊNCIAS BIBLIOGRÁFICAS}

1. Bücherl W. Escorpiões e escorpionismo no Brasil. I. Manutenção de escorpiões em viveiros e extração do veneno. Memórias do Instituto Butantan 25:53-82, 1953.

2. Bücherl W.Acúleos que matam. Editora da Revista dos Tribunais, São Paulo p.1-153, 1979.

3. Lourenço WR. Sur la systématique des scorpions appartenant an complexe Tityus stigmurus 
Cruz EFS, Yassuda CRW, Jim J, Barraviera B. Programa de controle do surto de escorpião Tityus serrulatus, Lutz e Mello 1922, no municipio de Aparecida, SP, (Scorpiones, Buthidae). Revista da Sociedade Brasileira de Medicina Tropical 28: 123-128, abr-jun, 1995.

(Thorell, 1877) (Butbidae). Revista Brasileira de Biologia 41:351-362, 1981.

4. Matthiesen FA. Partenogenesis in scorpions. Evolution 16:255-256, 1962.

5. Matthiesen FA.The breeding of Tityus serrulatus, Lutz e Mello 1922, in captivity. Revista Brasileira de Pesquisas Médicas e Biológicas 4:299-300, 1971.

6. Spirandeli-Cruz EF. Biologia dos escorpiões. In: Barraviera $B$ (ed) Venenos animais: uma visão integrada, Editora de Publicações Científicas, $1^{2}$ edição, Rio de Janeiro p.135-150, 1994. 